\title{
CARACTERIZAÇÃO DO MATERIAL INCONSOLIDADO DE FEIRA DE SANTANA (BA) A PARTIR DE ENSAIOS TÁCTEIS E VISUAIS
}

\author{
Igor Ferreira de Almeida'; Gracinete Bastos de Souza²; Luciana Correia Alcântara \\ Matos $^{3}$; Nadine de Jesus Santos ${ }^{4}$ \\ 1. Bolsista PROBIC/UEFS, Graduando em Engenharia Civil, Universidade Estadual de Feira de Santana, e-mail: \\ igor.almeidaig@gmail.com \\ 2. Orientadora, Departamento de Exatas, Universidade Estadual de Feira de Santana, e-mail: graciesouza@gmail.com \\ 3. Participante do projeto Integração de Dados dos Aspectos do Meio Físico do Município de Feira de Santana, BA, \\ Departamento de Tecnologia, Universidade Estadual de Feira de Santana, e-mail: lucianacamatos@ gmail.com \\ 4. Participante do projeto Integração de Dados dos Aspectos do Meio Físico do Município de Feira de Santana, BA, \\ Departamento de Tecnologia, Universidade Estadual de Feira de Santana, e-mail: nadinesanttos@gmail.com
}

PALAVRAS-CHAVE: material inconsolidado; tácteis visuais; Feira de Santana.

\section{INTRODUÇÃO}

O mapeamento geotécnico é um dos meios mais importantes para o estudo e o planejamento do meio físico, de modo que sejam respeitadas as suas limitações, a fim de que os problemas causados devido ao crescimento populacional e a expansão da área urbana sejam amenizados. A contribuição do mapeamento geotécnico para o planejamento do meio físico pode ocorrer de diversas formas e finalidades, uma delas é o estudo de aspectos geotécnicos do material inconsolidado, como textura, granulometria, coesão e outras propriedades importantes para melhorar as questões relacionadas ao uso e ocupação do solo.

A definição das características básicas do material inconsolidado pode ser feita através de identificação de simples reconhecimento, ou táctil visual, que é feita a partir de ensaios simples e resultados estimados do estado do material de acordo com a sua reação ao manuseio. Por meio dos ensaios tácteis visuais é possível avaliar propriedades como textura, plasticidade, coesão e outras características que permitem classificar o material de acordo com a sua granulometria.

Esse trabalho tem o objetivo de caracterizar e classificar o material inconsolidado do município de Feira de Santana, com base em amostras coletadas nos distritos de Maria Quitéria, Jaguara e Tiquaruçú, por meio de análises tácteis visuais e de granulometria, para contribuir no conhecimento de informações sobre o aspecto do meio físico do município, que poderão ser usadas para melhor compreender o seu espaço e desenvolver uma ocupação mais adequada.

\section{METODOLOGIA}

Para a realização desse trabalho foi feita uma revisão bibliográfica sobre ensaios tácteis visuais e de granulometria, principalmente das normas que especificam esses ensaios (NBR 7250/82 e NBR 7181/84) e de informações sobre a região estudada. Durante o período de pesquisa foram realizados trabalhos de campo, nos quais foram coletadas amostras de material inconsolidado próximo às principais estradas vicinais do município. Fez-se os ensaios de 20 amostras no Laboratório de Mecânica dos Solos da Universidade Estadual de Feira de Santana e a partir dos resultados obtidos foi feita a classificação do material inconsolidado da região. 


\section{RESULTADOS E DISCUSSÃO}

Foram analisadas 20 amostras de material inconsolidado, as quais foram coletadas em profundidades entre 30 e 80 centímetros, com o auxílio de uma pá, e foram colocadas em sacos transparentes e identificadas, sendo anotadas todas as informações de cor, umidade, aspectos climáticos do dia da coleta e localização por GPS.

A partir da mistura de uma pequena quantidade do material amostrado com água, manuseando-o cuidadosamente, foi possível classificar o solo granulometricamente, sabendose que:

- Areias são ásperas ao tato, apresentam partículas visíveis a olho nu, pouca ou nenhuma plasticidade e na maioria das vezes permitem o reconhecimento de minerais.

- Silte apresenta uma certa aspereza, porém não tão acentuada quanto das areias, mas também são sensíveis ao tato. O silte é classificado como um solo fino e possui baixa plasticidade.

- As argilas quando secas possuem textura fina, e os grãos não são visíveis a olho nu. Quando misturadas com água e trabalhadas, as argilas possuem alta plasticidade.

Foram realizados testes de plasticidade, aderência, mobilidade de água intersticial, resistência do torrão seco, desagregação do material submerso e dispersão em água para verificar as propriedades e caracterizar o material inconsolidado amostrado. Para aprimorar a classificação foram realizados ensaios de peneiramento para verificar a granulometria do material. Os ensaios realizados estão apresentados na figura 1.

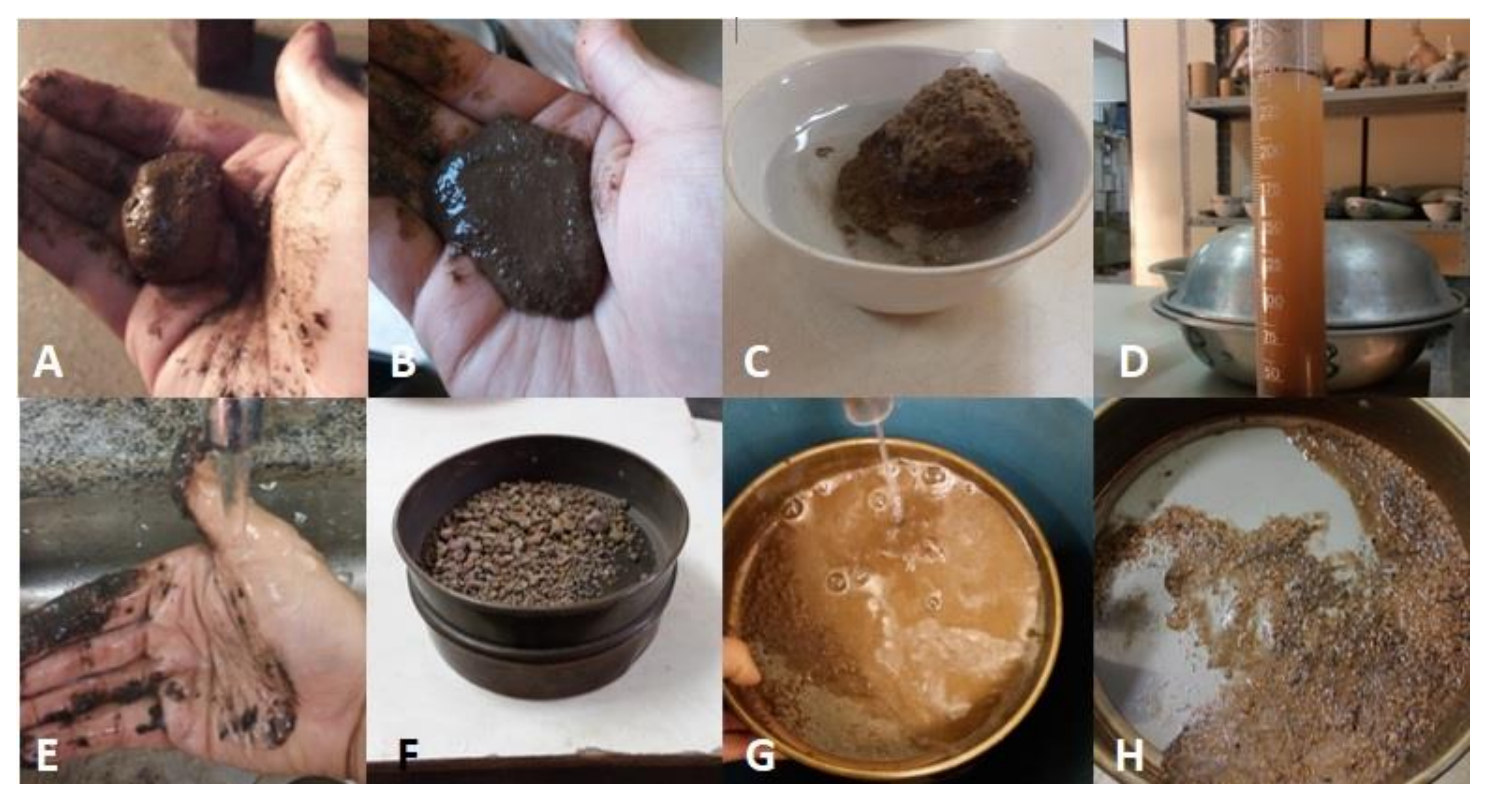

Figura 1: Ensaios realizados para caracterização do material inconsolidado. A- Teste de plasticidade. B- Teste de mobilidade da água intersticial. C- Teste de desagregação do material submerso. D- Teste de dispersão em água. E- Teste de sujar as mãos (aderência). F- Peneiramento para retenção do solo grosso na peneira de 2,0 $\mathrm{mm}$. G e H- Lavagem de material na peneira de $0,075 \mathrm{~mm}$ para verificar quantidade de solo fino.

Segundo a NBR 7250/82, a nomenclatura do solo deve ser feita conforme o comportamento da fração predominante, adjetivada com a fração de solo que puder também ser identificada. A nomenclatura deve ainda ser acompanhadas pela indicação da cor do material logo após a coleta e pela designação claro ou escuro. 
Com base nos ensaios realizados, as amostras de material inconsolidado foram classificados de acordo com as suas propriedades e granulometria, seguindo a classificação especificada pela NBR 7250/82. As nomenclaturas para cada amostra estão apresentadas na Tabela 1.

Tabela 1. Classificação das amostras estudadas de acordo com a NBR 7250.

\begin{tabular}{cl}
\hline Amostra & Classificação \\
\hline $\mathbf{1}$ & Areia pouco argilosa cinza escuro \\
\hline $\mathbf{2}$ & Areia cinza claro \\
\hline $\mathbf{3}$ & Areia argilosa vermelho claro \\
\hline $\mathbf{5}$ & Argila cinza escuro \\
\hline $\mathbf{6}$ & Areia cinza escuro \\
\hline $\mathbf{7}$ & Arlte arenoso marrom escuro \\
\hline $\mathbf{8}$ & Areia argilosa marrom escuro \\
\hline $\mathbf{9}$ & Areia siltosa marrom claro \\
\hline $\mathbf{1 0}$ & Areia siltosa marrom claro \\
\hline $\mathbf{1 1}$ & Areia pouco siltosa cinza claro \\
\hline $\mathbf{1 2}$ & Areia argilosa marrom escuro \\
\hline $\mathbf{1 3}$ & Areia cinza claro \\
\hline $\mathbf{1 4}$ & Areia argilosa marrom escuro \\
\hline $\mathbf{1 5}$ & Areia argilosa marrom escuro com pedregulho \\
\hline $\mathbf{1 6}$ & Argila pouco arenosa marrom escuro com pedregulho \\
\hline $\mathbf{1 7}$ & Areia pouco siltosa marrom claro \\
\hline $\mathbf{1 8}$ & Areia pouco siltosa marrom claro \\
\hline $\mathbf{1 9}$ & Areia cinza claro com pedregulho \\
\hline $\mathbf{2 0}$ & Areia pouco arenosa amarelo com pedregulho \\
\hline
\end{tabular}

A figura 2 mostra a visão geoespacial da localização de cada uma das amostras coletadas. A figura foi elaborada no SPRING, um Sistema de Informações Geográficas (SIG), desenvolvido pelo Instituto Nacional de Pesquisas Espaciais - INPE.

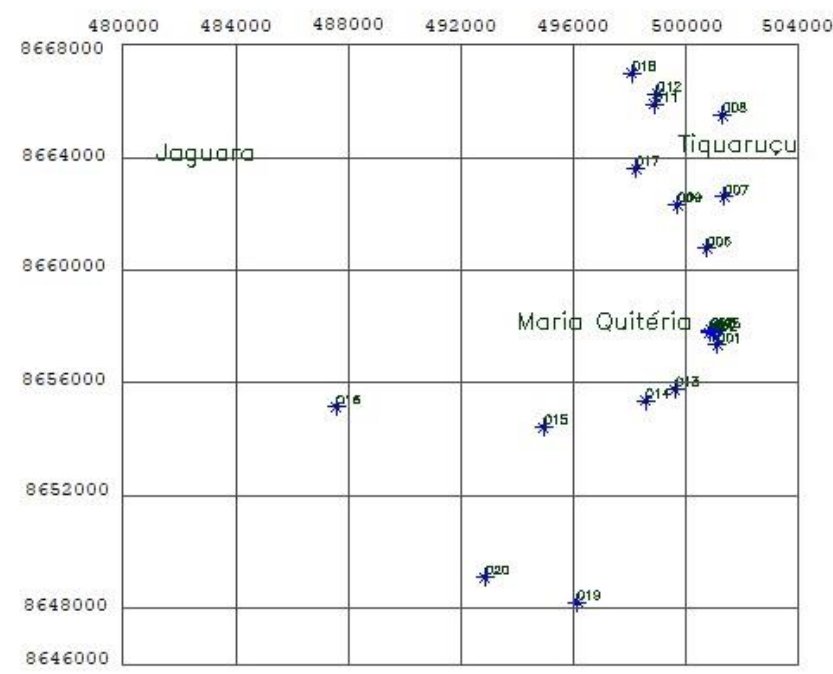

Figura 2. Visão geoespacial da localização das amostras ensaiadas. 


\section{CONCLUSÃO}

Com base no que foi estudado no decorrer do trabalho de pesquisa através da revisão bibliográfica, conclui-se que o material inconsolidado de Feira de Santana é composto por uma camada superficial de material arenoso. Essa informação foi confirmada através da realização dos ensaios em laboratório das amostras coletadas no município.

Foram ensaiadas 20 amostras de material inconsolidado, das quais 17 apresentaram características e granulometria de areias, com variação na cor (geralmente marrom e cinza) e de outras frações de solo e pedregulho.

Apesar de ser uma caracterização simples, as análises realizadas permitiram comparar as informações da literatura com a prática e orientar os estudos sobre o material inconsolidado da região, que podem ser utilizadas para pesquisas futuras que tenham objetivos de avaliar propriedades mais específicas do solo local e que necessitem de informações mais básicas para o embasamento do trabalho. Além disso, esse trabalho pode contribuir no conhecimento sobre o aspecto do meio físico do município, o que é fundamental para melhor compreender seu espaço e desenvolver uma ocupação mais adequada.

\section{REFERÊNCIAS}

ABNT- Associação Brasileira de Normas Técnicas. NBR 7181/1984- Solo- Análise Granulométrica- Método de Ensaio. Rio de Janeiro, ABNT.

ABNT- Associação Brasileira de Normas Técnicas. NBR 7250/1982- Identificação e descrição de amostras de solos obtidas em sondagens de simples reconhecimento dos solos. Rio de Janeiro, ABNT.

BASTOS, G. (1996). Estudo com Sistema de Informação Geográfica para o Mapeamento Geotécnico do Município de Feira de Santana - BA. Dissertação de Mestrado, Publicação GDM - 035A/96, Departamento de Engenharia Civil, Universidade de Brasília, Brasília, DF, 114.

COLLARES, Eduardo Goulart et al. A CARACTERIZAÇÃO DOS MATERIAIS INCONSOLIDADOS NA COMPARTIMENTAÇÃO GEOTÉCNICA DA REGIÃO DE BRAGANÇA PAULISTA - SÃO PAULO. Rev. 10. São Paulo, Volume Especial 1995.

PINTO, Carlos de Sousa. Curso básico de Mecânica dos Solos em 16 Aulas. $2^{\text {a }}$ Edição. Oficina de textos, São Paulo, 2000.

SPRING: Integrating remote sensingand GIS by object-oriented data modeling. Camara G, Souza RCM, FreitasUM, Garrido J Computers \& Graphics, 20: (3) 395-403, May-Jun 1996.

SUPERINTENDÊNCIA DE ESTUDOS ECONÔMICOS E SOCIAIS DA BAHIA - SEI. Base Cartográfica do Estado da Bahia. 2008. 